\title{
Kimyasal Püskürtme Tekniği ile Üretilen PbS İnce Filmin Karakterizasyonu
}

\section{Characterization of PbS Thin Film Produced by Chemical Spray Pyrolysis Technique}

\author{
Sema Kurtaran ${ }^{1 *}$ \\ Geliş / Received: 23/06/2021 \\ Revize / Revised: 06/10/2021 \\ Kabul / Accepted: 08/10/2021 \\ ÖZ \\ $\mathrm{Bu}$ çalışmada, kurşun sülfür $(\mathrm{PbS})$ filmler, kolay ve ekonomik bir yöntem olan ultrasonik kimyasal püskürtme \\ tekniği ile $370 \pm 5^{\circ} \mathrm{C}$ taban sıcaklığında mikroskop cam üzerine kaplanmıştır. Farklı molariteli Pb katkısı ile elde \\ edilen PbS filmlerin, yapısal, yüzeysel, optik ve elektriksel özellikleri üzerindeki etkisi incelendi. Optik, yapısal, \\ yüzeysel ve elektriksel özellikleri, UV spektrofotometre, taramalı elektron mikroskobu, Atomik kuvvet \\ mikroskobu ve X-1şını spektroskopisi analizi kullanılarak karakterize edildi. X-ışınları kııınımı (XRD) analizinden \\ $\mathrm{PbS}$ ince filminin hekzagonal yapıya sahip olduğu bulundu. Atomik Kuvvet Mikroskobu (AFM) ölçümlerinden \\ $\mathrm{PbS}$ ince filminin pürüzlülükleri belirlendi. Optik soğurma spektrumundan $\mathrm{PbS}$ ince filminin 1.69-1.89 eV'luk dar \\ optik bant aralığına sahip olduğu belirlendi. Üretilen filmlerin kalınlık değerleri ise spektroskopik elipsometre \\ tekniğinde Cauchy-Urbach modeli kullanılarak belirlendi. PbS filmlerinin fotovoltaik güneş pili uygulamaları için \\ kullanım potansiyeli araştırılmıştır.
}

Anahtar Kelimeler- Kurşun Sülfür (PbS), Kimyasal Püskürtme Yöntemi, İnce Film

\begin{abstract}
In this study, lead sulfide $(\mathrm{PbS})$ films were coated on microscope glass at the substrate temperature of $370 \pm 5^{\circ} \mathrm{C}$ by ultrasonic chemical spray pyrolysis technique, which is an easy and economical method. The effect of $\mathrm{PbS}$ films obtained with different molarity $\mathrm{Pb}$ additions on their structural, surface, optical, and electrical properties was investigated. Their optical, structural, surface, and electrical properties were characterized using UV, spectrophotometer, scanning electron microscopy, Atomic force microscopy, and X-ray spectroscopy analyses. From the X-ray diffraction (XRD) analysis, the $\mathrm{PbS}$ thin film was found to have a hexagonal structure. The roughness of the $\mathrm{PbS}$ thin film was determined by Atomic Force Microscopy (AFM). From the optical absorption spectrum, it was calculated that the $\mathrm{PbS}$ thin film has a narrow optic band gap of 1.69-1.89 eV. The thickness values of the produced films were determined using the spectroscopic ellipsometry technique. The Cauchy-Urbach model was used to determine the thickness of the films. The potential for use of $\mathrm{PbS}$ films for photovoltaic solar cell applications was investigated.
\end{abstract}

Keywords- Lead Sulphide (PbS), Spray Pyrolysis, Thin Film

1*Sorumlu yazar iletişim: skurtaran@ogu.edu.tr (https://orcid.org/0000-0003-2069-4719)

Fizik Bölümü, Eskişehir Osmangazi Üniversitesi, Fen Edebiyat Fakültesi, Eskişehir, Türkiye 


\section{GİRİ̧}

Fotovoltaik güneş pili üretiminde kullanılan malzemelerin maliyetlerinin azaltılması, teknolojinin basitleştirilmesi yönünde yapılan araştırma ve geliştirme çalışmalarında yarıiletken ince filmler ilgi odağ olmuştur. Kurşun sülfür (PbS) kızılötesi dedektör olarak işlev gören kızılötesi yayıcılar ve güneş enerjisi uygulamaları için kullanılan kristal ve polikristal yapılara sahip olmasından dolayı tercih edilen malzemeler arasındadır [1] PbS, 0.41 eV'lik dar enerji bant aralığı ve büyük bir Bohr yarıçapı olması nedeniyle önemli ilgi görmüş önemli bir IV-VI grubu yarı iletkendir [2]. PbS, enerji bant aralığı ayarlanabilen, çeşitli nanoyapılara yol açan çeşitli optik ve elektriksel özelliklere sahip ilginç bir malzemedir. Güneş pili üretim teknolojileri, düşük maliyetli ve toksik olmayan kurşun sülfüre yönelmiştir. $\mathrm{PbS}$ ince film malzemesi genellikle $0.40 \mathrm{ila} 2.34 \mathrm{eV}$ arasında özelleştirilmiş enerji aralığı ile p-tipi iletken yapı sergiler [3]. PbS ince filmler mükemmel foto iletken doğaya ve iyi güneş kontrol özelliklerine sahiptir [4,5]. Eşsiz özelliklerinden dolayı, IR dedektörler, diyot lazerler, transistörler, kontak doğrultucular gibi ve güneş absorpsiyonu ve foto-direnç gibi uygulamalarda çeşitli cihazlarda kullanılmaktadır [6]. PbS ince filmler, kimyasal banyo biriktirme [6-9], elektrobiriktirme [10], döndürme kaplama biriktirme [11], kimyasal püskürtme [2,3,12,13], rf saçtırma [14], katı buhar katkılama [15] gibi farklı fiziksel ve kimyasal biriktirme teknikleri kullanılarak hazırlanmıştır. Kimyasal püskürtme tekniği ekonomik ve basit olması açısından oldukça tercih edilmektedir. Bu çalışmada, fotovoltaik güneş pili teknolojisindeki kullanım alanlarını incelemek ve geliştirmek amaciyla $\mathrm{PbS}$ filmleri ultrasonik kimyasal püskürtme tekniği (UKP) ile $370 \pm 5^{\circ} \mathrm{C}$ sıcaklığındaki mikroskop camları üzerine biriktirilerek elde edilmiştir. Ultrasonik püskürtme tekniği (USP), kalınlık kontrolü, düşük sıcaklık gereksinimi, elementi seçme özgürlüğü, kompozisyon ve geniş alan biriktirme için ucuz, basit ve kullanışlıdır.

\section{MATERYAL VE YÖNTEM}

$\mathrm{Bu}$ çalışmada $\mathrm{PbS}$ fillmlerinin üretiminde kullanılan ultrasonik kimyasal püskürtme sisteminin (UKP) tasarımı, literatürde [16,17] sunulan teori ve konfigürasyonlara dayanmaktadır. UKP tekniğinde üretilen filmlerin kristalleşme dereceleri kullanılan mikroskop camlarının temiz olmasına ve yüzeylerinin düzgünlüğüne güçlü derecede bağlıdır. Bu çalışmada PbS filmlerinin üretimi için kullanılan mikroskop camları üretimden önce 1x1 $\mathrm{cm}^{2}$ boyutlarında kesilmiş ve deterjanlı suda yıkama işlemine tabi tutulmuş, daha sonra da saf su ile yıkanmış ve kurutulmuştur. Kurutulan mikroskop camları film üretimine hazır hale getirilmiştir. PbS filmi kimyasal püskürtme deney düzeneği kullanılarak, sulu bir çözelti püskürtülerek 1sıtılmış mikroskop camı üzerine biriktirilir. PbS filmleri üretmek için kurşun nitrat $\left[\mathrm{Pb}\left(\mathrm{NO}_{3}\right)_{2}\right]$ ve tiyoüre $\left[\left(\mathrm{NH}_{2}\right)_{2} \mathrm{CS}\right]$ kimyasalları kullanılmıştır. $0.01 \mathrm{M} \mathrm{Pb}\left(\mathrm{NO}_{3}\right)_{2}$ ve $0.05 \mathrm{M}\left[\left(\mathrm{NH}_{2}\right)_{2} \mathrm{CS} 200 \mathrm{ml}\right.$ ' başlangıç püskürtme çözeltisi çözücü olarak saf su kullanılarak hazırlanmıştır. PbS1 olarak kodlanmıştır. Daha sonra $0.05 \mathrm{M} \mathrm{Pb}\left(\mathrm{NO}_{3}\right)_{2}$ ve $0.05 \mathrm{M}\left(\mathrm{NH}_{2}\right)_{2} \mathrm{CS} 200 \mathrm{ml}$ başlangıç püskürtme çözeltisi çözücü olarak yine saf su kullanılarak hazırlanmıştır. PbS5 olarak kodlanmıştır. Mikroskop camlarının yüzey sıcaklığı demir konstantan termoçift ile ölçülmüştür. Mikroskop camı ile termoçift arasındaki 1sıl temas indiyum ile sağlanmıştır. Ultrasonik püskürtme başlığının titreşim frekansı $100 \mathrm{kHz}$ ve taşıyıcı gaz olarak hava (1 bar) kullanılmıştır. Mikroskop cam ile püskürtme başlığı arasındaki mesafe $\sim 30 \mathrm{~cm}$ olarak ayarlanmıştır. Püskürtme çözeltisi, $5 \mathrm{ml} / \mathrm{dk}$ akış hızında $\sim 10 \mathrm{dk}$ süreyle $370 \pm 5^{\circ} \mathrm{C}$ sıcaklığındaki mikroskop camları üzerine püskürtülmüştür. Püskürtme işlemi bittikten sonra elde edilen filmler püskürtme odasında 10-15 saat soğumaya bırakılmıştır. Üretilen $\mathrm{PbS}$ ince filmlerin yapısal, yüzeysel, optik ve elektriksel karakterizasyonu için çeşitli teknikler kullanıldı. $\mathrm{PbS}$ ince filmlerin yapısal özelliklerini analiz etmek için Panalytical Empyrian cihazı ile $\mathrm{CuK}_{\alpha} 1$ şıması $(\lambda=1.5406$ Å) (X-ışını kırınım ölçeri) kullanıldı. PbS ince filmlerin yüzey morfolojisini analiz etmek için ise, Zeiss SUPRA 40VP SEM (taramalı elektron mikroskopu) ayrıca 3-boyutlu görüntüleri ve pürüzlülükleri Park Systems XE-100 AFM (atomik kuvvet mikroskopu) cihazı kullanıldı. SchimadzuUV-2550 UV-VIS spektrofotometresi kullanılarak geçirgenlik ölçüldü ve optik metot kullanılarak filmlerin optik bant aralığı hesaplandı. Filmlerin kalınlıkları, PHE 102 Spektroskopik Elipsometre (SE) ölçümlerinden 1200-1600 nm spektral aralığı boyunca $70^{\circ}$ 'lik bir geliş açısında kaydedildi. Daha sonra, özdirenç değerleri Keithley 2601A System Source Meter Four-prob. kurulumu kullanılarak elde edildi.

\section{BULGULAR VE TARTIŞMA}

\section{A. Yapısal Özellikler}

$\mathrm{PbS}$ filmlerinin XRD desenleri Şekil 1'de verilmektedir. Şekil 1 incelendiğinde, kırınım desenlerinde farklı şiddet ve genişliklere sahip pikler bulunmaktadır. Genel olarak pik şiddetlerinin düşük olması ve yarı pik genişliklerinin geniş olması filmlerin kristalleşme düzeylerinin biraz kötü olduğunu göstermektedir. PbS filmleri polikristal ve hekzagonal kristal yapıdadır(ICDD card No.01-080-5758). PbS1 filminde (1 0 2) ve (l 0 l 6 6) pikleri 
mevcuttur. Desenler incelendiğinde, PbS1 filminde tercihli yönelim (102) olarak görülmektedir. PbS5 filminde ise kristal yapının oldukça kötüleştiği görülmektedir.

Bir kırınım pikinin genişlemesi $(\beta)$,tane boyutuna $(D)$ Scherrer formülü [18] ile bağlıdır.

$$
D=\frac{0.9 \lambda}{\beta \operatorname{Cos} \theta}
$$

Burada tane boyutu $(D)$, ilgili kristal yönü için yarı pik genişliği $(\beta)$ ve $(\theta)$ Bragg açısı, $\lambda$ kullanılan X-ışınının $\left(\mathrm{CuK}_{\alpha}(1.5406)\right)$ dalga boyudur.

Dislokasyon yoğunluğu $(\delta)$, malzemenin belirli bir kısmında bulunan dislokasyonlarının bir ölçüsüdür. Yani, birim alanı kesen dislokasyon çizgi sayısıdır. Dislokasyon yoğunluğu [19],

$$
\delta=\frac{1}{D^{2}}
$$

ifadesi kullanılarak hesaplanır. Minumum $\delta$ değeri için 1 değeri yazılır. Küçük $\delta$ değerleri malzemenin kristalleşme seviyesinin iyi olduğunu gösterir[20,21].

Piklerin pozisyonlarındaki hafif kaymalar sıkışmış veya genişlemiş örgü düzlemlerine sahip tanelerin bulunduğunu gösterir. Makro Gerilme $\langle e\rangle$,

$$
\langle e\rangle=\frac{d-d_{0}}{d_{0}}
$$

Denklemi ile ifade edilir. Buradaki $\langle e\rangle$ malzemedeki makro gerilmeleri, $d$ düzlemler arası mesafeyi ve $d_{0}$ deformasyon olmadı̆̆ı durumdaki düzlemler arası mesafeyi göstermektedir [22].

Örgü parametreleri,

$$
\frac{1}{d^{2}}=\frac{4}{3} \frac{\left(h^{2}+h k+k^{2}\right)}{a^{2}}+\frac{l^{2}}{c^{2}}
$$

eşitliği kullanılarak hesaplanır [23]. PbS1 filmi için elde edilen örgü parametreleri $a=b=4.3035 \AA$ ve $c=8.4117$ olarak hesapland1. XRD verilerini kullanarak elde edilen yapisal parametreler Tablo 1'de verilmektedir.
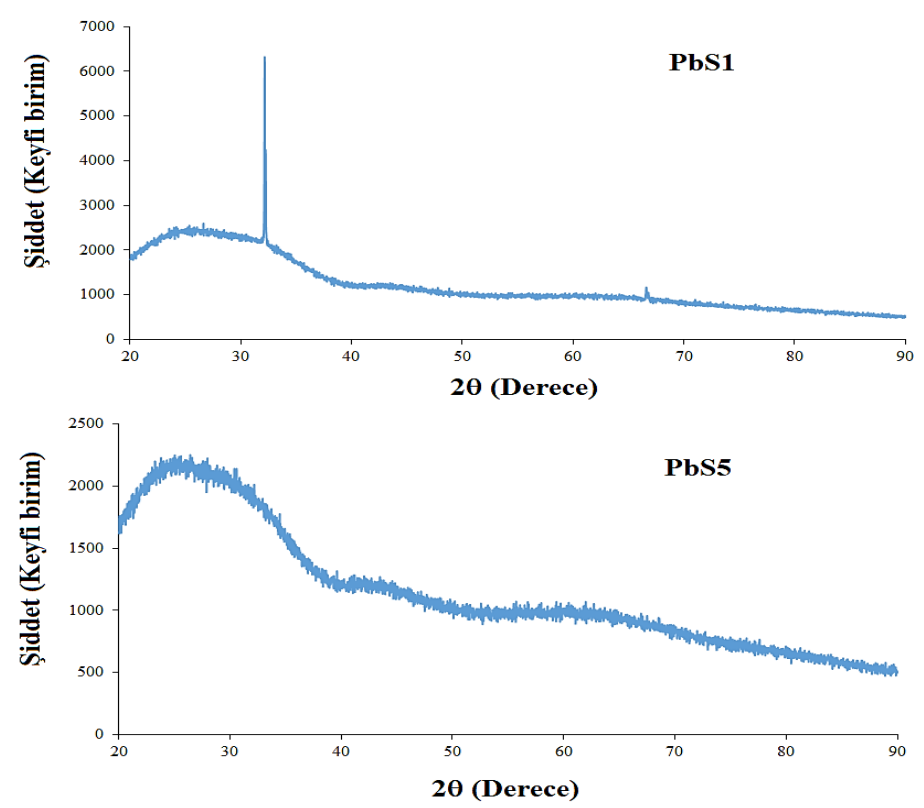

Şekil 1. PbS filmlerinin XRD desenleri 
Tablo 1. PbS filmlerinin yapısal parametreleri

\begin{tabular}{|c|c|c|c|c|c|c|c|c|c|}
\hline Film & $2 \theta\left(^{\circ}\right)$ & $d(\AA)$ & $2 \theta_{0}\left(^{\circ}\right)$ & $d_{0}(\AA)$ & $\beta\left(\left(^{\circ}\right)\right.$ & $D(\mathbf{n m})$ & $\langle e\rangle$ & $\begin{array}{c}\delta \times 10^{-} \\
{ }^{5}\left(1 / \mathbf{n m}^{2}\right)\end{array}$ & (hkl) \\
\hline \multirow{2}{*}{ PbS1 } & 32.152 & 2.78174 & 32.490 & 2.75358 & 0.0468 & 177 & 0.0102 & 3.192 & (102) \\
\hline & 66.614 & 1.40279 & 67.216 & 1.39167 & 0.0624 & 152 & 0.0079 & 4.328 & (006) \\
\hline
\end{tabular}

\section{B. Optik Özellikler}

$\mathrm{PbS}$ filmlerinin kalınlıkları spektroskopik elipsometre kullanılarak belirlenmiş̧tir. UKP tekniği ile üretilen filmler tam olarak düzgün ve homojen olarak elde edilememektedir. PbS filmlerinin üretilmesinde kullanılan üretim tekniğinden, yüzeylerdeki pürüzlülükten, tane sınırlarından ve yüzey morfolojisinden kaynaklandığını düşünmekteyiz. Ayrıca numuneden yansıyan ışık polarizasyon durumunda değişikliğe sebep olmaktadır ve burum ise deneysel olarak ölçülen değerlerinde sapmalara neden olmaktadır. Tablo 2'de PbS filmlerinin kalınlıkları verilmiştir.

Tablo 2. PbS filmlerinin kalınlıkları ve yasak enerji aralıkları

\begin{tabular}{ccc}
\hline Film & Kalınlık(nm) & $\mathbf{E}_{\mathbf{g}}(\mathbf{e V})$ \\
\hline $\mathrm{PbS} 1$ & 142 & 1.69 \\
$\mathrm{PbS5}$ & 145 & 1.89 \\
\hline
\end{tabular}

$\mathrm{PbS}$ filmlerinin UV spektrometresi ile alınan geçirgenliklerinin dalga boyuna göre değişim grafikleri Şekil 2'de verilmektedir. Şekil 2 incelendiğinde $\mathrm{PbS}$ filmlerin görünür bölgede $\sim \%$ geçirgenliğe sahip olduğu belirlenmiştir. Optik bant aralığı,

$$
\alpha h v=A\left(h v-E_{g}\right)^{m}
$$

denklemi verilmektedir. Burada A sabit, $E_{g}$ materyalin optik bant aralığı ve m=1/2 izin verilen doğrudan geçişleri ifade eder [24]. Şekil 3, soğurma verilerinden faydalanarak her bir film için $(\alpha h v)^{2}$ nin $h v^{\prime}$ ye göre değişim grafikleridir. Bu grafiklerin lineer kısımlarının doğrultusunun $h v$ eksenini $(\alpha h v)^{2}=0$ ' da kestiği nokta $E_{g}$ değerini verir. $E_{g}$ değerleri Tablo 2’ de verilmektedir.

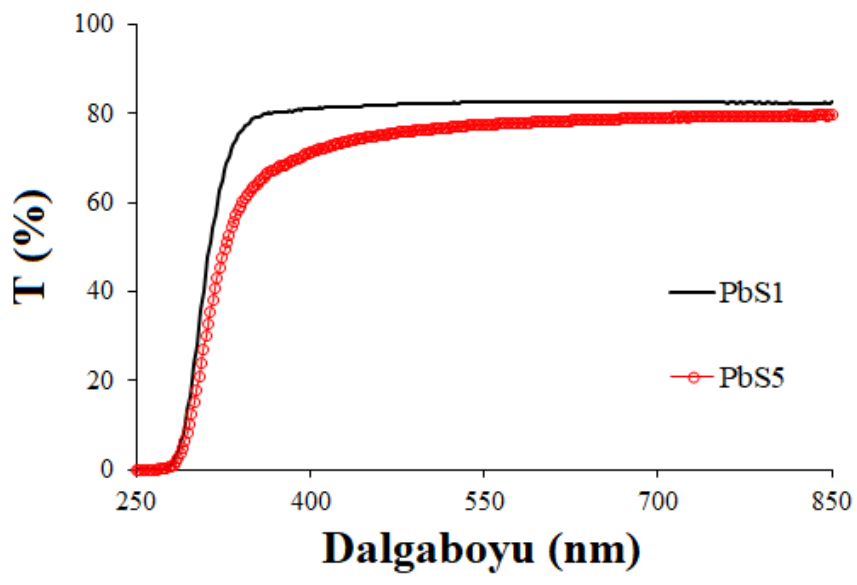

Şekil 2. PbS filmlerinin geçirgenlik spektrumları 

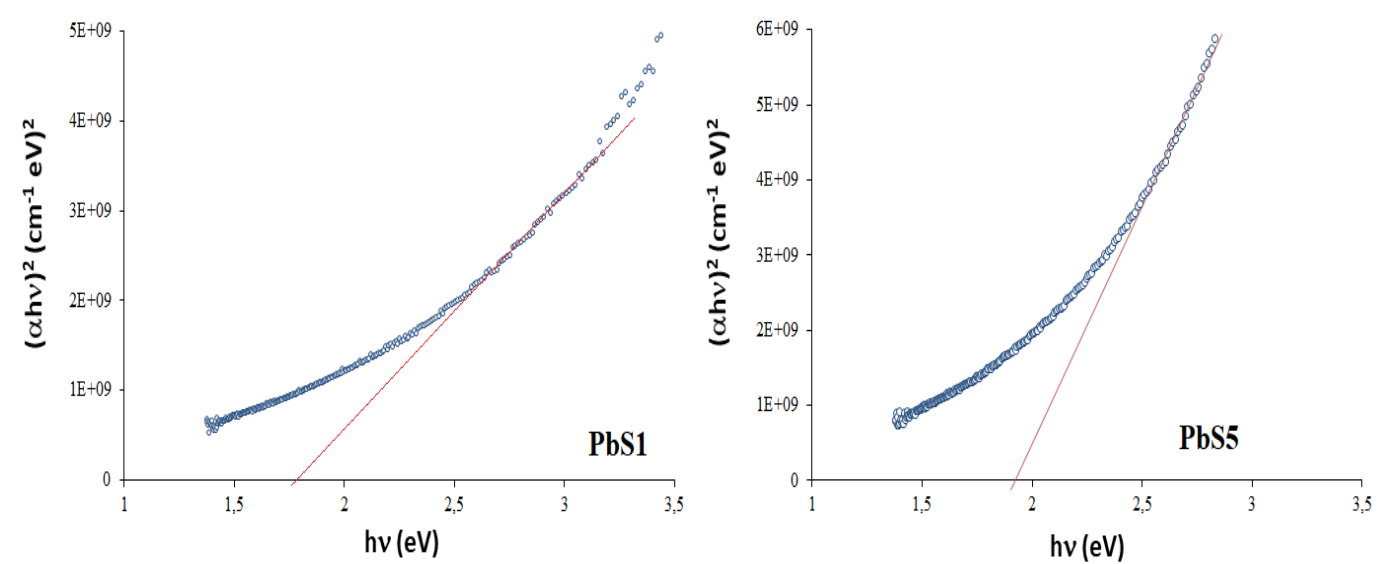

Şekil 3. PbS filmlerinin $(\alpha h v)^{2}$ 'ninhv' ye göre değişim grafikleri

Raman cihazı hızlı ve duyarlı olması, az örnek gerektirmesi, kullanım kolaylığı ve malzemeye zarar vermeme özellikleri göz önüne alındığında teknolojik ve bilimsel araştırmalarda önemlidir. Genel olarak, kristal bir malzemenin spektrumu keskin ve yoğun Raman tepeleri gösterirken, amorf veya çok kristalli numune geniş ve daha az yoğun Raman tepeleri sunar [25]. Şekil 4 'de gösterildiği gibi, PbS spektrumları yaklaşık 139, 278, 480, 563, 945 ve $1074 \mathrm{~cm}^{-1}$ de bant göstermiştir. $139 \mathrm{~cm}^{-1}$ civarında tepe, muhtemelen uzunlamasına ve enine akustik olan fonon modlarının kombinasyonuna veya büyük olasılıkla enine optik ve akustik fononların kombinasyonuna atfedilmiştir [26-29]. Yaklaşık $278 \mathrm{~cm}^{-1}$ deki tepe noktası PbS'nin iki fonon işlemlerine $\left(2 \times 139=278 \mathrm{~cm}^{-1}\right)$ atanmıştır[28-31]. $480 \mathrm{~cm}^{-1}$ civarındaki pik PbS'de lokalize 2LO fononları tarafından saçılmaya atfedilir [30]. 563ve $945 \mathrm{~cm}^{-1}$ ' deki pikler, PbS'nin foto degradasyonuna atanır ve kurşun oksisülfatlar için karakteristik piklerdir [32].Yaklaşık $850 \mathrm{~cm}^{-1}$ deki tepe noktası, CC germe veya $\mathrm{RNH}_{2}$ sallanma modlarından kaynaklanabilir [33,34].
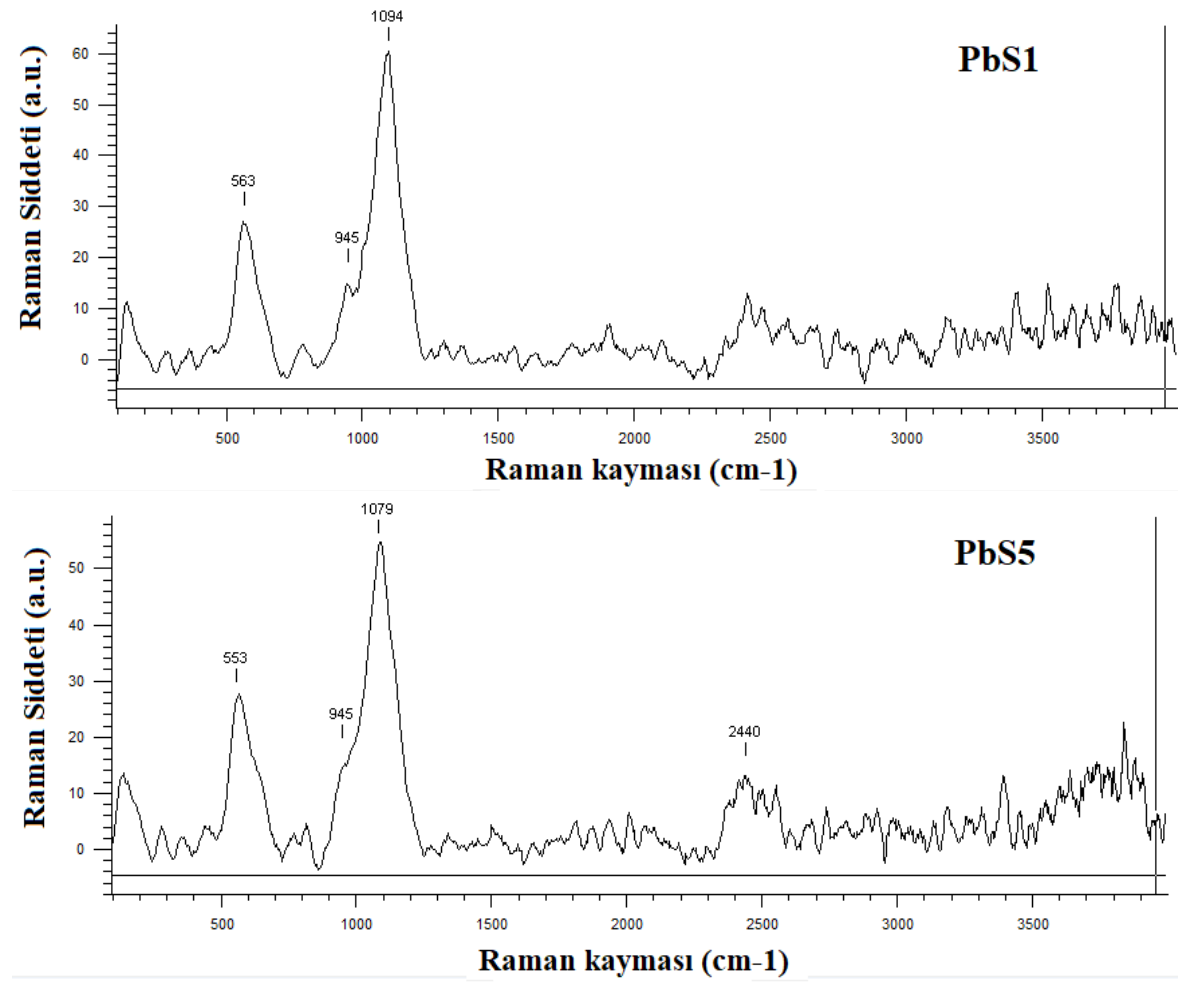

Şekil 4. PbS filminin Raman spektrumu 


\begin{tabular}{|c|c|c|}
\hline & $\begin{array}{l}\text { BŞEÜ Fen Bilimleri Dergisi } \\
8(2), 770-777,2021\end{array}$ & $\begin{array}{r}\text { BSEU Journal of Science } \\
\text { https://doi.org/10.35193/bseufbd } 956725\end{array}$ \\
\hline $\begin{array}{l}\text { CIKSEEY EDEBALI } \\
\text { IVERSITES| }\end{array}$ & & 2458-7575 (https://dergipark.org.tr/tr/pub/bseufbd) \\
\hline
\end{tabular}

\section{Yüzeysel Özellikler}

Şekil 5'de PbS filmlerinin SEM görüntüleri verilmektedir. PbS filmlerine ait görüntülerden görüldüğü gibi yüzey homojen değildir ve bazı küresel parçacıklar yüzey üzerinde rastgele dağıllmıştır. PbS1 numunesinde daha homojen dağılmış ve birbirine daha iyi tutunmuş yüzey oluşumu, PbS5 numunesinde ise fazla miktarda yı̆̆ılma ve dislokasyon şeklinde kusurlar mevcuttur.

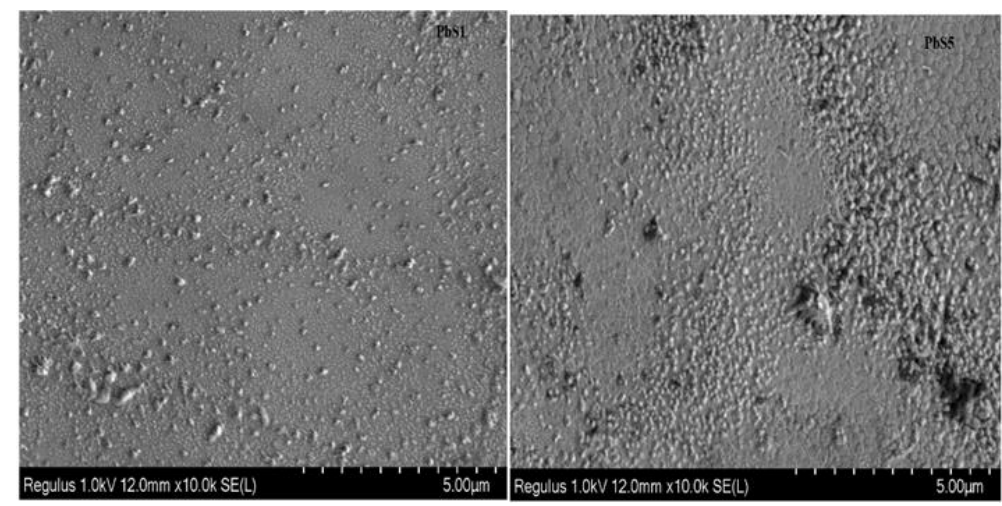

Şekil 5. PbS filmlerinin SEM görüntüleri

Atomik Kuvvet Mikroskobu (AFM), filmlerin morfolojik bilgilerini ve yüzey pürüzlülüğ̈̈nü araştırmak için önemli bir araçtır. Şekil 6, PbS ince filmlerin 3 boyutlu AFM görüntülerini temsil eder. Yüzey görüntüleri filmlerin küresel şekilli tanelere ve dar boyut dağıllımına sahip pürüzsüz bir yüzeye sahip olduğunu göstermektedir
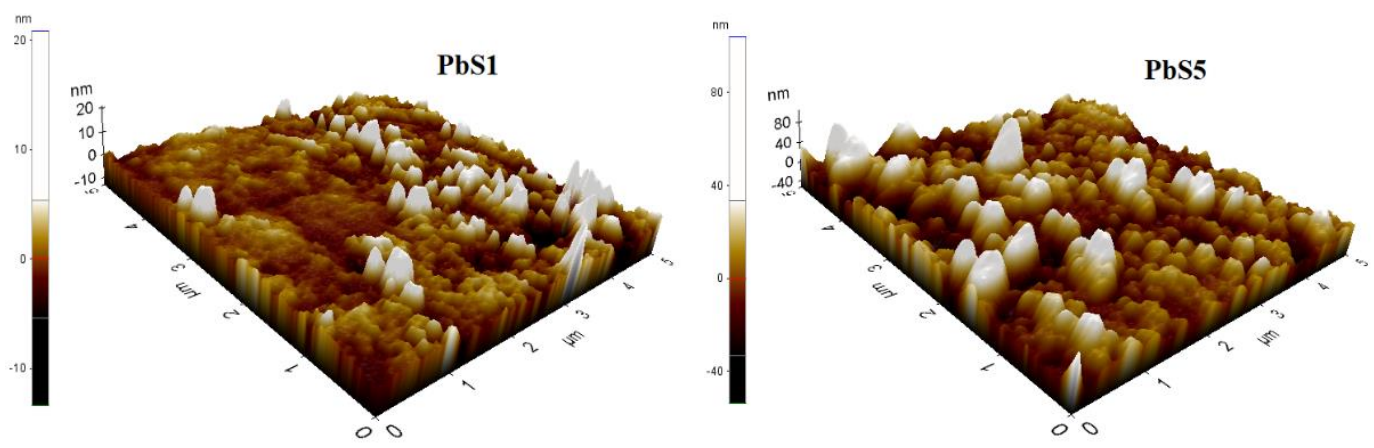

Şekil 6. PbS filmlerinin AFM görüntüleri

Ölçülen yüzey pürüzlülüğü $\mathrm{PbS5}^{\prime}$ de $\mathrm{PbS1}$ ' e göre artmıştır. Bu tür pürüzlülük artması, XRD çalışmasından kanıtlandığı gibi tane boyutunun değişimi ile uyumludur. AFM görüntülerinden elde edilen parçacık boyutu $176 \mathrm{~nm}$ ve $195 \mathrm{~nm}$. PbS1'in parçacık boyutu PbS5 den büyüktür. AFM' den elde edilen değerin XRD ile elde edilen tane boyutundan farklı olması beklenmektedir. Çünkü iki veya daha fazla tanenin bir arada bulunabileceği oluşumlardan elde edilmektedir. Filmlerin pürüzlülük değerleri $50 \mathrm{~nm}$ altında olduğu için teknolojik uygulamalar için arzu edilir.

Tablo 3. PbS filmlerinin pürüzlülükleri ve parçacık boyutu

\begin{tabular}{cccc}
\hline Film & $\mathbf{R}_{\boldsymbol{q}}(\mathbf{n m})$ & $\mathbf{R}_{\mathbf{a}}(\mathbf{n m})$ & Parçacık boyutu (nm) \\
\hline $\mathrm{PbS} 1$ & 11 & 8 & 195 \\
$\mathrm{PbS} 5$ & 17 & 13 & 176 \\
\hline
\end{tabular}




\section{Elektriksel Özellikler}

Elektriksel özdirenç, yarıiletken malzemelerde elektron taşıma olayları hakkında bilgi vermekte önemli rol oynar. Elektrik özdirenç değerlerini elde etmek için dört problu özdirenç yöntemi kullanıldı. Elektriksel özdirenç PbS1 ve PbS5 için sırasılyla $1.85 \times 10^{5} \Omega \mathrm{cm}$ ve $2.03 \times 10^{5} \Omega \mathrm{cm}$ olarak ölçülmüştür.PbS5 filminin özdirencindeki artış kristalleşme seviyesi kötüleştiğinden dolayıdır.

\section{SONUÇLAR}

$\mathrm{PbS}$ ince filmi kolay ve ekonomik bir yöntem olan kimyasal püskürtme yöntemi ile mikroskop camı üzerine biriktirildi. Filmlerin yapısal, optik, yüzeysel ve elektriksel özellikleri incelendi. Filmlerin XRD analizi, üretilen PbS filminin polikristal ve hekzagonal yapıda olduğunu ortaya çıkardı. PbS1 filmi için tercihli yönelimin (1 $\left.\begin{array}{ll}0 & 2\end{array}\right)$ doğrultusunda olduğu, Pb katkısı arttığında kristal yapının bozulduğu görülmektedir. Tane boyutu tercihli yönelimde yaklaşık $177 \mathrm{~nm}$ bulunmuştur. Elde edilen numunelerin optik bant aralığ $1.68-1.89 \mathrm{eV}$, yığın halindeki PbS'den daha yüksektir. Maviye kayan optik bant aralığı, PbS'yi fotovoltaik uygulamalar için uygun katman olarak kullanışlı hale getirir. Yüzey pürüzlülüğü $\mathrm{AFM}$ tekniği ile analiz edilen $\mathrm{PbS}$ filmlerinin yüzey pürüzlülüŭg̈, malzemelerin optik özellikleri için önemli bir parametredir. Sonuç olarak, PbS ince filmler, yüksek optik iletkenlikleri nedeniyle optoelektronik cihazlarda ve pürüzsüz yüzeyleri nedeniyle gaz sensörlerinde kullanılabilir.

\section{KAYNAKLAR}

[1] Göde, F., Güneri, E., Eman, F. M., Kafadar, V. E. \& Ünlü, S. (2014). Synthesis, structural, optical, electrical and thermoluminescence properties of chemically deposited PbS thin films. Journal of Luminescence, 147, 41-48.

[2] Rajashree, C., Balu, A. R \& Nagarethinam, V. S. (2015). Properties of Cd doped PbS thin films: doping concentration effect. Surface Engineering, 31(4), 316-321.

[3] Rex Rosario, S., Kulandaisamy, I., Deva Arun Kumar, K., Arulanantham, A. M. S, Valanarasu, S., Youssef, M. A. \& Awwad, N. S. (2019). Deposition of p-type Al doped PbS thin films for hetero structure solar cell device using feasible nebulizer spray pyrolysis technique. Physica B: Physics of Condensed Matter, 575, 411704.

[4] Thangaraju, B., \& Kaliannan, P. (2000). Polycrystalline lead tin chalcogenide thin film grown by spray pyrolysis. Crystal Research and Technology: Journal of Experimental and Industrial Crystallography, 35(1), 71-75.

[5] Pentia, E., Pintillie, L., Matei, I., Botillia, T. \& Ozbay, E. (2001). Chemically Prepared Nanocrystalline PbS Thin Films. Journal of Optoelectronics and Advanced Materials 3, 525-530.

[6] Kul, M. (2019). Characterization of PbS Film Produced by Chemical Bath Deposition at Room Temperature. Eskişehir Technical University Journal of Science and Technology B-Theoretical Sciences, 7(1), 46 -58.

[7] Al Din, N. S., Hussain, N. \& Jandow, N. (2016). Structural and optical studied of nano structured lead sulphide thin films prepared by the chemical bath deposition technique. AIP Conference Proceedings. 1758, $020002(7 \mathrm{p})$.

[8] Thirumavalavana, S., Mani, K. \& Suresh, S. (2015). Investigation on structural, optical, morphological and electrical properties of lead sulphide (PbS) thin films. Journal of Ovonic Research, 11, 123-130.

[9] Beddek, L., Messaoudi, M., Attaf, N., Aida, M. S. \& Bougdira, J. (2016). Sulfide precursor concentration and lead source effect on PbS thin films properties. Journal of Alloys and Compounds, 666, 327-333.

[10] Mathews, N. R., Angeles-Chavez, C., Cortes-Jacome M. A. \& Toledo-Antonio, J. A. (2013). Physical properties of pulse electrod eposited lead sulphide thin films. Electrochimica Acta, 99, 76- 84.

[11] J. Patel, J., Mighri, F., Ajji, A., Tiwari, D. \& Chaudhuri, T. K. (2014). Spin-coating deposition of PbS and CdS thin films for solar cell application. Applied Physics A, 117, 1791-1799.

[12] Thangaraju, B. \& Kaliannan, P. (2000). Spray pyrolytically deposited PbS thin films. Semiconductor Science and Technology, 15, 849-853.

[13] Faraj, M. G. (2015). Effect of thickness on the structural and electrical properties of spray pyrolysed lead sulphide thin films. American Journal of Condensed Matter Physics, 5, 51-55.

[14] Motlagh, Z. \& Araghi, M. E. A. (2016). Effect of film thickness and texture morphology on the physical properties of lead sulphide thin films. Semiconductor Science and Technology, 31, 025017 (11).

[15] Boadi, N.O, McNaughter, P. D., Helliwell, M., Malik, M. A., Awudza, J. A. M. \& O’Brien, P. (2016). The deposition of $\mathrm{PbS}$ and $\mathrm{PbSe}$ thin films from lead dichalcogenoimido phosphinates by AACVD. Inorganica Chimica Acta, 453, 439-442. 
[16] Kurtaran, S., Aldağ, S., Öföfoğlu, G., Akyüz, I. \& Atay, F. (2016). Transparent conductive ZnO thin films grown by chemical spray pyrolysis: the effect of Mg. Journal of Materials Science: Materials in Electronics, 27, 8478-8485.

[17] Atay, F., Köse, S., Bilgin, V. \& Akyüz, I. (2003). CdS:Ni films obtained by ultrasonic spray pyrolysis:effect of the Ni concentration. Materials Letters, 57, 3461-3472.

[18] Cullity, B. D. \& Stock, S. R. (2001). Elements of X-ray Diffraction. Pearson Prentice Hall, USA.

[19] Williamson, G. B. \& Smallman, R. C. (1956). Dislocation densities in some annealed and cold-worked metals from measurements on the X-ray Debye-Scherrer spectrum. Philosophical Magazine Series A: Series, 8(1), 34-46.

[20] Rajashree, C. \& Balu, A. R. (2016). Tuning the physical properties of PbS thin films toward sopto electronic applications through Ni doping. Optik, 127, 8892-8898.

[21] Touati, B., Gassoumi, A., Dobryden, I., Natile, M. M., Vomiero, A. \& Turki, N. K. (2016). Engineering of electronic and optical properties of $\mathrm{PbS}$ thin films via $\mathrm{Cu}$ doping. Superlattices and Microstructures, 97, 519528.

[22] Vigil, O., Cruz, F., Acevedo, A. M., Puente, G. C., Vaillant, L. \& G. Santana, G. (2001). Structural and optical properties of annealed $\mathrm{CdO}$ thin films prepared by spray pyrolysis. Materials Chemistry and Physics, 68, 249-252.

[23] Manjula, N., Usharan,i K., Balu, A. R., Nagarethinam, V. S. (2014). Studies on the physical properties of three potentially important TCO thin films fabricated by a simplified spray technique under same deposition conditions. International Journal of ChemTech Research, 6(1), 705-718.

[24] Pankove J. I. (1975). Optical Process in Semiconductors. New York, USA: Dover.

[25] Chen, J. H., Chao, C. G., Ou, J. C., \& Liu, T. F. (2007). Growth and characteristics of lead sulphide nanocrystals produced by the porous alumina membrane. Surface Science, 601, 5142-5147.

[26] Perez R. G., Tellez G. H., Rosas, U. P., Torres, A. M., Tecorralco, J. H., Lima, L. C., \& Moreno, O. P. (2013). Growth of PbS nanocrystals thin films by chemical bath. Journal of Materials Science and Engineering A, 3, $1-13$.

[27] Sherwin, R., Clark, R. J. H., Lauck, R., \& Cardona, M. (2005). Effect of isotope substitution and doping on the Raman spectrum of galena (PbS). Solid State Communications, 134, 565-570.

[28] Cao, H., Wang, G., Zhang, S., \& Zhang, X. (2006). Growth and photoluminescence properties of PbS nanocubes. Nanotechnology, 17, 3280-3287.

[29] Tohidi, T., Jamshidi-Ghaleh, K., Namdar, A., \& Abdi-Ghaleh, R. (2014). Comparative studies on the structural, morphological, optical, and electrical properties of nanocrystalline $\mathrm{PbS}$ thin films grown by chemical bath deposition using two different bath compositions. Materials Science in Semiconductor Processing, 25,197-206.

[30] Milekhin, A., Sveshnikova, L., Duda, T., Surovtsev, N., Adichtchev, S., \& Zahn, D. R. T. (2011). Optical phonons in nanoclusters formed by the Langmuir-Blodgett technique. Chinese Journal of Physics, 49, 63-70.

[31] Krauss, T. D., Wise, F. W., \& Tanner, D. B. (1996). Observation of coupled vibrational modes of a semiconductor nanocrystal. Physical Review Letters, 76, 1376-1379.

[32] Batonneau, Y., Bremard, C., Laureyns, J., Merlin, J. C. (2000). Microscopic and imaging Raman scattering study of $\mathrm{PbS}$ andits photo-oxidation products. Journal of Raman Spectroscopy, 31, 1113-1119.

[33] Lynch, M. (2017). An investigation of solutions of sulfur in oleylamine by Raman spectroscopy and their relation to lead sulphide quantum dot synthesis. Under graduate honorstheses, University of Colorado, Boulder, Colorado, USA.

[34] Ramaswamy, S., Rajaram, R. K., \& Ramakrishnan, V. (2005). Infrared and laser Raman spectra of bis (DLmethioninium) sulfate. Journal of Raman Spectroscopy, 36, 840-847. 